\title{
Metastatic Lung Neuroendocrine Neoplasm
}

National Cancer Institute

\section{Source}

National Cancer Institute. Metastatic Lung Neuroendocrine Neoplasm. NCI Thesaurus.

Code C157602.

A neuroendocrine neoplasm that arises from the lung and has spread to another anatomic site. 